\title{
Heats of vaporization of room temperature ionic liquids by tunable vacuum ultraviolet photoionization
}

\author{
Steven D. Chambreau, ${ }^{1}$ Ghanshyam L.Vaghjiani, ${ }^{2 *}$ Albert To ${ }^{3}$ \\ Christine Koh, ${ }^{4}$ Daniel Strasser, ${ }^{4 \dagger}$ Oleg Kostko, ${ }^{4}$ and Stephen R. Leone ${ }^{4}$ \\ ${ }^{1}$ ERC, Incorporated, Edwards Air Force Base, California 93524 \\ ${ }^{2}$ Air Force Research Laboratory, Edwards Air Force Base, California 93524 \\ ${ }^{3}$ Department of Civil and Environmental Engineering, \\ University of Pittsburg, Pittsburgh, Pennsylvania 15261 \\ ${ }^{4}$ Departments of Chemistry and Physics, and Lawrence Berkeley National Laboratory, \\ University of California, Berkeley, California 94720
}

\begin{abstract}
The heats of vaporization of the room temperature ionic liquids (RTILs) N-butyl-Nmethylpyrrolidinium bistrifluorosulfonylimide, N-butyl-N-methylpyrrolidinium dicyanamide, and 1-butyl-3-methylimidazolium dicyanamide are determined using a heated effusive vapor source in conjunction with single photon ionization by a tunable vacuum ultraviolet synchrotron source. The relative gas phase ionic liquid vapor densities in the effusive beam are monitored by clearly distinguished dissociative photoionization processes via a time-of-flight mass spectrometer at a tunable vacuum ultraviolet beamline 9.0.2.3 (Chemical Dynamics Beamline) at the Advanced Light Source synchrotron facility. Resulting in relatively few assumptions, through the analysis of both parent cations and fragment cations, the heat of vaporization of N-butyl$\mathrm{N}$-methylpyrrolidinium bistrifluorosulfonylimide is determined to be $\Delta \mathrm{H}_{\text {vap }}(298.15 \mathrm{~K})=$ $195 \pm 19 \mathrm{~kJ} \mathrm{~mol}^{-1}$. The observed heats of vaporization of 1-butyl-3-methylimidazolium dicyanamide $\left(\Delta \mathrm{H}_{\mathrm{vap}}(298.15 \mathrm{~K})=174 \pm 12 \mathrm{~kJ} \mathrm{~mol}^{-1}\right)$ and N-butyl-N-methylpyrrolidinium dicyanamide $\left(\Delta \mathrm{H}_{\mathrm{vap}}(298.15 \mathrm{~K})=171 \pm 12 \mathrm{~kJ} \mathrm{~mol}^{-1}\right)$ are consistent with reported experimental values using electron impact ionization. The tunable vacuum ultraviolet source has enabled accurate measurement of photoion appearance energies. These appearance energies are in good agreement with MP2 calculations for dissociative photoionization of the ion pair. These experimental heats of vaporization, photoion appearance energies, and $a b$ initio calculations corroborate vaporization of these RTILs as intact cation-anion ion pairs.
\end{abstract}

Keywords: pyrrolidinium, dicyanamide, RTIL, ion pair, PI-TOFMS, synchrotron

\footnotetext{
* Corresponding author: ghanshyam.vaghjiani@edwards.af.mil, 10 East Saturn Boulevard, Edwards AFB, CA 93524, Fax: (661) 275-5471. ${ }^{\dagger}$ Current address: Institute of Chemistry, Hebrew University, Jerusalem 91904, Israel.
}

Distribution A: Approved for public release; distribution unlimited 


\section{PREPRINT}

\section{Introduction}

Ionic liquids are classified as ionic salts that have melting points at and below $\mathrm{T}=$ $100{ }^{\circ} \mathrm{C}$. Room temperature ionic liquids (RTILs) are liquids under ambient conditions. RTILs represent a new class of "green" solvents that potentially can replace highly volatile organic solvents and hydrazine-based hypergolic fuels. ${ }^{1-4}$ RTILs typically have large, multi-atom cations such as ammonium, pyrrolidinium, imidazolium, triazolium, and tetrazolium ions that have diffuse positive charge distributions and non-polar alkyl functional groups (Figure 1). The diffuse nature of the ionic charges, combined with the large effective cation-anion distance in RTILs results in relatively low lattice energies. By contrast, a typical ionic salt, $\mathrm{NaCl}$ (melting point $\mathrm{T}=801{ }^{\circ} \mathrm{C}$ ), has very localized charge distributions on each ion, and the separation between cation and anion is small, therefore a strong Coulombic attraction exists between sodium and chloride ions in the condensed phase. As a result, the lattice energy of $\mathrm{NaCl}$ is much higher than for RTILs, and the phase transition from ionic solid to liquid occurs at a much higher temperature in $\mathrm{NaCl}$ than for RTILs.

Due to their ionic nature, RTILs were originally thought to have essentially no vapor pressure. Recent studies of RTILs in vacuum have demonstrated that some RTILs can be distilled in vacuum with little thermal degradation, ${ }^{5-8}$ as noted in more detail below. Transpiration and Knudsen methods $^{9}$ have also been applied to vaporize and recover RTIL condensates. ${ }^{10-13}$ To evaluate the thermal stability of a compound, studies such as differential scanning calorimetry (DSC) and thermal gravimetric analysis (TGA) are typically carried out at atmospheric pressure. ${ }^{11,12,14-16}$ Recent TGA studies have shown that significant mass loss of RTILs can occur at temperatures well below the onset

Distribution A: Approved for public release; distribution unlimited 
decomposition temperatures reported in DSC studies. ${ }^{16}$ Such loss in mass could represent depletion through vaporization of intact RTILs.

The ionic nature of RTILs may lead to dramatically different vaporization mechanisms than for molecular liquids. For protic RTILs (having an $\mathrm{H}$ bound to a nitrogen in the cation ring), typically a proton is transferred to the anion during vaporization and neutral species are formed: ${ }^{7}$

$$
[\mathrm{AH}]^{+}[\mathrm{B}]^{-} \rightarrow \mathrm{A}+\mathrm{BH}
$$

These neutrals can be volatilized, and upon condensation, the RTIL can be reformed by proton exchange to the weaker acid (the reverse of Reaction 1 above). The groundbreaking study by Earle et al. ${ }^{5}$ demonstrated that when aprotic RTILs (having only alkyl groups bound to the cation ring nitrogens) are heated in a vacuum, recovery of the vapor produced the same RTIL with little or no degradation for several families of RTILs. Vaporization of mixtures of RTILs showed that one component was successfully enriched upon fractional distillation due to the differences in vapor pressure of one RTIL versus another. ${ }^{7}$ The thermal stability of certain families of RTILs was attributed to the weak nucleophilicity (tendency to react with carbon) of the anion. Initially, the vaporization mechanism was proposed to be via cluster formation in the gas phase. ${ }^{5}$ More recent studies using photoionization, ${ }^{17}$ line of sight mass spectrometry, ${ }^{18,19}$ Fourier transform ion cyclotron resonance, ${ }^{6,7}$ and field desorption/ionization ${ }^{20}$ mass spectrometric techniques suggest that vaporization of these thermally stable species is via neutral ion pair formation in the gas phase. However, aprotic RTILs with strongly nucleophilic anions can react when heated, and the recovery of pure RTIL by vacuum distillation may not be feasible.

Distribution A: Approved for public release; distribution unlimited 


\section{PREPRINT}

Theoretical modeling of RTILs ${ }^{21}$ has been of great interest in order to predict such important properties as heats of formation, heats of vaporization, ${ }^{11,22}$ melting and boiling points, viscosity, and thermal decomposition mechanisms. ${ }^{23}$ Dynamics calculations have indicated that vaporization to produce an intact ion pair is energetically favored over ion cluster formation (multiple cation-anion ion pairs), where larger clusters have higher heats of vaporization. ${ }^{24}$ The ionic nature of these liquids has made predicting these properties difficult and very few experimental data exist to confirm theoretical heats of formation and heats of vaporization values, quantities that are essential for evaluating RTIL performance as propellants.

The implication that RTILs evaporate as intact ion pairs is based on detection of the intact cation by mass spectrometry using photoionization or electron-impact ionization, as well as photoelectron spectroscopy and calculation. It is accepted that photoionization or electron impact ionization of the neutral ion pair, followed by dissociation, leads to a cation and a neutral, and the cation is then detected by the mass spectrometer:

$$
\left[\mathrm{A}^{+} \mathrm{B}\right]^{-}+h v \rightarrow\left[\mathrm{A}^{+} \mathrm{B}\right]+\mathrm{e}^{-} \rightarrow \mathrm{A}^{+}+\mathrm{B}+\mathrm{e}^{-}
$$

Direct detection of the ion pair has been elusive, most likely because of the use of relatively high energies of the ionizing photons $(23.2 \mathrm{eV})$ or electrons $(10-100 \mathrm{eV})$ versus the energy required to dissociate the ion pair:

$$
\left[\mathrm{BMIM}^{+}[\mathrm{dca}]^{-} \rightarrow \mathrm{BMIM}^{+}+\mathrm{dca}^{-} \quad \Delta \mathrm{H}=3.59 \mathrm{eV} \text { at } 298 \mathrm{~K}(\mathrm{G} 3 \mathrm{MP} 2)^{10}\right.
$$

where $[\mathrm{BMIM}]^{+}[\mathrm{dca}]^{-}$is the RTIL 1-butyl-3-methylimidazolium dicyanamide. However, recent progress has been made towards direct detection of ion pairs. ${ }^{20}$

Distribution A: Approved for public release; distribution unlimited 


\section{PREPRINT}

In this study, a first report is provided for determinations of the heats of vaporization of room temperature ionic liquids by tunable synchrotron photoionization detection. Several ionic liquids, N-butyl-N-methylpyrrolidinium bistrifluorosulfonylimide, $\left[\mathrm{pyrr}_{14}\right]^{+}\left[\mathrm{NTf}_{2}\right]^{-}, \mathrm{N}$-butyl-N-methylpyrrolidinium dicyanamide, [pyrr $\left._{14}\right]^{+}[\mathrm{dca}]^{-}$, and 1-butyl-3-methylimidazolium dicyanamide, $[\mathrm{BMIM}]^{+}[\mathrm{dca}]^{-}$, are studied by means of an effusive vapor source coupled to a vacuum ultraviolet photoionization time of flight mass spectrometer (PI-TOFMS). An analysis of the strengths of the photoionization method is made, which include the ability to study the heats of vaporization of the ionic liquid molecules at the tunable thresholds for dissociative photoionization, good comparisons between the $\Delta \mathrm{H}_{\mathrm{vap}}$ results from several fragment masses, and an ability to assess the temperature dependence of the photoionization cross sections. Furthermore, the comparison of experimental photoion appearance energies with theory supports a dissociative photoionization mechanism. To

our knowledge, this study is the first reported measurement of the heat of vaporization of $\left[\operatorname{pyrr}_{14}\right]^{+}\left[\mathrm{NTf}_{2}\right]^{-}$. The heats of vaporization of $[\mathrm{BMIM}]^{+}[\mathrm{dca}]^{-}$and $\left[\operatorname{pyrr}_{14}\right]^{+}[\mathrm{dca}]^{-}$obtained here are in reasonable agreement with previously reported experimental measurements.

\section{Experimental}

The experiments are performed on the Chemical Dynamics Beamline, a tunable VUV beamline 9.0.2.3 at the Advanced Light Source in Berkeley, California. Product masses are detected as a function of vaporization temperature of the ionic liquid and tunable photoionization wavelength. The PI-TOFMS repeller is pulsed at $10 \mathrm{kHz}$ and typically data are accumulated for 200,000 pulses per mass spectrum. For $\left[\operatorname{pyrr}_{14}\right]^{+}[\mathrm{dca}]^{-}$, 200,000 pulses are accumulated at $12.0 \mathrm{eV}$ photon energy at $473 \mathrm{~K}, 483 \mathrm{~K}$, and $493 \mathrm{~K}$.

Distribution A: Approved for public release; distribution unlimited 


\section{PREPRINT}

For $\left[\text { pyrr }_{14}\right]^{+}\left[\mathrm{NTf}_{2}\right]^{-}$and $[\mathrm{BMIM}]^{+}[\mathrm{dca}]^{-}$, photoionization efficiency (PIE) data were acquired as the VUV photon energy is scanned from 8.0 to $15.0 \mathrm{eV}$ in $0.2 \mathrm{eV}$ steps (photon energy resolution was $0.025 \mathrm{eV}$ ). The effusive beam is oriented counterpropagating to the VUV beam. In this first study, PIE data are taken over a limited temperature range, at $468 \mathrm{~K}$ and $483 \mathrm{~K}$ for $[\mathrm{BMIM}]^{+}[\mathrm{dca}]^{-}$, and at $583 \mathrm{~K}$ and 613 $\mathrm{K}$ for $\left[\operatorname{pyrr}_{14}\right]^{+}\left[\mathrm{NTf}_{2}\right]^{-}$. In addition, data for $\left[\operatorname{pyrr}_{14}\right]^{+}\left[\mathrm{NTf}_{2}\right]^{-}$are also accumulated at 12.6 $\mathrm{eV}$ and at $15.0 \mathrm{eV}$ for longer signal averaging of 9 million pulses per spectrum at both $583 \mathrm{~K}$ and $613 \mathrm{~K}$.

The RTIL source is a modified version of a source described previously. ${ }^{17}$ Briefly, the source uses a Pyrex reservoir that has a narrow outlet tube (Figure 2). Each region is surrounded by a machined aluminum block. Each block is heated separately by 4 cartridge heaters embedded evenly around the cell axis. The heaters in each region are controlled by separate power supplies (0-40 W per region), and thermal equilibrium within the source is reached before PIE curves are measured. The temperatures in each region are measured using previously calibrated type $\mathrm{K}$ thermocouples and from the uniformity of the heated regions and thermocouple readings, the temperature values reported here are assessed to have an error of $\pm 3 \mathrm{~K}$. Although the temperatures of the reservoir and outlet regions can be controlled separately, for heat of vaporization determinations the temperature of the reservoir region is set to be equal to the outlet region. In order to examine pyrolysis of ion pairs in the gas phase, the temperature of the outlet region can be set at a higher temperature than the reservoir region, and pyrolysis experiments will be described in a future publication. The experimental temperatures are selected by performing differential scanning calorimetry (DSC) on the ionic liquids prior

Distribution A: Approved for public release; distribution unlimited 


\section{PREPRINT}

to the photoionization experiments. The temperatures are selected to be well below the decomposition temperatures of the ionic liquids to avoid pyrolysis.

The raw mass spectra are corrected for fluctuations in the power of the light source by monitoring the power at a VUV photodiode whose wavelength response curve had previously been characterized. The synchrotron is operated in constant top off mode and the ring current is kept constant at $500 \mathrm{~mA}$. Low source temperature spectra are scaled and subtracted from the high temperature data to remove any background signals not due to the RTIL. Figure 3 shows a typical corrected mass spectrum. PIE curves are determined by integrating the peak areas of a given mass in each photon energy mass spectrum. Appearance energies were determined by a linear regression of the first 5 points above the signal-to-noise ratio, with an estimated uncertainty of $\pm 0.2 \mathrm{eV}$.

1-butyl-3-methylimidazolium dicyanamide (>98\%) and N-butyl-Nmethylpyrrolidinium dicyanamide $(>99 \%)$ are obtained from EMD. N-butyl-Nmethylpyrrolidinium bistrifluorosulfonylimide (>98\%) is purchased from Aldrich. In order to remove volatile impurities present in the sample, the RTIL samples are heated in high vacuum (base pressure $\sim 10^{-6}$ Pascals) for 12 hours prior to the experiments as follows: $\left[\operatorname{pyrr}_{14}\right]^{+}\left[\mathrm{NTf}_{2}\right]^{-}$at $453 \mathrm{~K}$, ppyrr $\left._{14}\right]^{+}[\mathrm{dca}]^{-}$at $378 \mathrm{~K}$, and $[\mathrm{BMIM}]^{+}[\mathrm{dca}]^{-}$at $358 \mathrm{~K}$.

$A b$ initio calculations are performed using Gaussian $03 \mathrm{~W}^{25}$ at the $\mathrm{HF} 6-31+\mathrm{G}(\mathrm{d}, \mathrm{p})$ or B3LYP $6-31+\mathrm{G}(\mathrm{d}, \mathrm{p})$ level of theory to preoptimize geometries. Final optimization and energy calculations are performed at the MP2 6-31+G(d,p) and M06 ${ }^{26} 6-31+\mathrm{G}(\mathrm{d}, \mathrm{p})$ levels of theory using GAMESS. ${ }^{27,28}$ Resulting MP2 and M06 energies at $0 \mathrm{~K}$ are corrected for unscaled zero-point vibrational energies. Based on previous calculations of RTIL ionization processes using HF 6-31+G(d,p), B3LYP 6-31+G(d,p), and MP2 6-

Distribution A: Approved for public release; distribution unlimited 


\section{PREPRINT}

$31+\mathrm{G}(\mathrm{d}, \mathrm{p})$ levels of theory, MP2 6-31+G(d,p) is selected as the preferred method due to good agreement with experimental ionization potentials and ionization trends. The MP2 $6-31+\mathrm{G}(\mathrm{d}, \mathrm{p})$ level of theory is assigned an uncertainty of $\pm 0.1 \mathrm{eV}$ based on our previous calculations. Due to complications with MP2 for $\left[\mathrm{pyrr}_{14}\right]^{+}[\mathrm{dca}]^{-}$explained below, M06 was used to calculate the ionization energies for $\left[\operatorname{pyrr}_{14}\right]^{+}[\mathrm{dca}]^{-}$.

\section{Results and Discussion}

As noted, a mass spectrum of $\left[\mathrm{pyrr}_{14}\right]^{+}\left[\mathrm{NTf}_{2}\right]^{-}$taken at $613 \mathrm{~K}$ and $15.0 \mathrm{eV}$ photon energy is shown in Figure 3, and the PIE curves for mass 142 at $583 \mathrm{~K}$ and $613 \mathrm{~K}$ and mass 84 at $613 \mathrm{~K}$ are shown in Figure 4. Mass 142 represents the $\left[\operatorname{pyrr}_{14}\right]^{+}$parent cation of the ionic liquid ion pair in the gas phase (equation 2). The appearance of mass 84 is due to fragmentation of the internally hot $\left[\operatorname{pyrr}_{14}\right]^{+}$cation, which can be attributed to $\mathrm{C}_{4} \mathrm{H}_{10}$ loss. From these curves, the appearance energies of the resulting intact cation and fragment cations can be determined, allowing insight into the energetics of ionization of the ion pair and possible ion fragmentation pathways. The observed appearance energies for masses 142 and 84 are $9.4 \pm 0.2$ and $10.0 \pm 0.2 \mathrm{eV}$, respectively, which are in excellent agreement with their corresponding MP2 appearance energies of $9.2 \pm 0.1$ and $10.1 \pm 0.1$ eV. The thermal contribution due to the small temperature differences in these experiments $(\leq 30 \mathrm{~K})$ should only amount to a few millielectron volts at the temperatures involved, causing a shift to lower appearance energy due to hot bands that is smaller than the resolution of our experiment.

By comparing the intensities of mass 142 peaks, which are proportional to the

number densities of the ion pair in the RTIL vapor, ${ }^{18}$ at two known source temperatures

Distribution A: Approved for public release; distribution unlimited 


\section{PREPRINT}

$\mathrm{T}_{1}$ and $\mathrm{T}_{2}$ and applying the Clausius-Clapeyron equation, the heat of vaporization in this temperature range is directly determined:

$$
\Delta \mathrm{H}_{\text {vap }}=-\mathrm{R} \ln \left(\mathrm{I}_{2} / \mathrm{I}_{1}\right)\left[\left(\mathrm{T}_{1} \mathrm{~T}_{2}\right) /\left(\mathrm{T}_{2}-\mathrm{T}_{1}\right)\right]
$$

where $\mathrm{I}$ is the measured mass 142 peak intensity, and $\mathrm{R}$ is the gas constant. Over the temperature range of this experiment, the photoionization cross section at a given photon energy is considered to be constant. The branching fractions from the ionized ion pair to intact cation or cation fragments are considered to be constant as well.

The heat of vaporization of $\left[\operatorname{pyrr}_{14}\right]^{+}\left[\mathrm{NTf}_{2}\right]^{-}$is determined using equation 4 and the data in the following ways: 1) using the sum of the intensities of all the points along the mass 142 tunable wavelength PIE curve (36 points with 7.2 million pulses total per curve) at $T_{1}$ and $T_{2}, 2$ ) by individually comparing the intensities at $T_{1}$ and $T_{2}$ of mass 142 at one specific wavelength, $12.6 \mathrm{eV}$, and 3) by analyzing the results also at $15.0 \mathrm{eV}$. A longer signal averaging condition of 9 million pulses is used for the last two cases. $\mathrm{T}_{1}$ and $\mathrm{T}_{2}$ are 583 and $613 \mathrm{~K}$, respectively. A similar analysis is performed for mass 84 also. Table 1 summarizes the experimental $\Delta \mathrm{H}_{\mathrm{vap}}$ values obtained. The experimental $\Delta \mathrm{H}_{\mathrm{vap}}$ values have been corrected to $298.15 \mathrm{~K}$ using a $\Delta \mathrm{C}_{\mathrm{p}}$ value of $-105.4 \mathrm{~J} \cdot \mathrm{K}^{-1} \cdot \mathrm{mol}^{-1}$ for $[\mathrm{BMIM}]^{+}[\mathrm{dca}]^{-}$and $\left[\mathrm{pyrr}_{14}\right]^{+}[\mathrm{dca}]^{-18},{ }^{18}$ and a value of $-94 \mathrm{~J} \cdot \mathrm{K}^{-1} \cdot \mathrm{mol}^{-1}$ for $\left[\mathrm{pyrr}_{14}\right]^{+}\left[\mathrm{NTf}_{2}\right]^{-10}$ The uncertainties in Table 1 represent twice the standard deviation of the measurements. The larger uncertainties in these measurements are the result of having fewer data points across similar temperature ranges for determining the heat of vaporization versus the more extensive maps versus temperature in the referenced works.

Good agreement for $\Delta \mathrm{H}_{\mathrm{vap}}$ calculated using masses 142 and 84 (170.5 vs. 162.9 $\mathrm{kJ} / \mathrm{mol}$, Table 1) indicates the possibility of calculating $\Delta \mathrm{H}_{\mathrm{vap}}$ from mass fragments of the

Distribution A: Approved for public release; distribution unlimited 


\section{PREPRINT}

cation, and mass 84 is used successfully to determine the $\Delta \mathrm{H}_{\mathrm{vap}}$ of $\left[\mathrm{pyrr}_{14}\right]^{+}[\mathrm{dca}]^{-}$. One possibility why mass 84 is usable for determining the heat of vaporization for the [pyrr $\left._{14}\right]^{+}$-containing RTILs may be due to its increased stability from possible resonance structures of the cation. ${ }^{18}$ This stability also could explain the significant fragmentation of the intact cation to mass 84 under such soft ionization conditions. When plotting $\ln I$ versus $1 / \mathrm{T}$ of mass 84 at 473,483 , and $493 \mathrm{~K}$, the heat of vaporization determined by the slope of these points agrees well with the averaged value $\left(\Delta \mathrm{H}_{\mathrm{vap}}\right.$ (slope) vs. $\Delta \mathrm{H}_{\mathrm{vap}}$ (average), Table 2). Mass 84 analysis for the heat of vaporization of $\left[\operatorname{pyrr}_{14}\right]^{+}[\mathrm{dca}]^{-}$ agrees reasonably well with the reported literature value (Table 2 ). For $[\mathrm{BMIM}]^{+}[\mathrm{dca}]^{-}$, masses $82,97,124$ and 137 are used to calculate the heat of vaporization, and the reported heat of vaporization value is slightly higher than the literature value (Table 1). The successful determination of $\Delta \mathrm{H}_{\mathrm{vap}}$ from fragment masses is important because for some RTILs the intact cation may not be detected. In fact, only a very weak parent cation ion peak at mass 142 is detected for $\left[\operatorname{pyrr}_{14}\right]^{+}[\mathrm{dca}]^{-}$and no parent peak at mass 139 is detected for $[\mathrm{BMIM}]^{+}[\mathrm{dca}]^{-}$. The present $\Delta \mathrm{H}_{\mathrm{vap}}$ of $\left[\mathrm{pyrr}_{14}\right]^{+}\left[\mathrm{NTf}_{2}\right]^{-}$is consistent with heats of vaporization determined for other $\mathrm{NTf}_{2}^{-}$based RTILs. ${ }^{6,12,13,22,24,29}$ The temperatures used in these experiments are well below the reported onset decomposition temperatures (non-zero DSC slope) for these species (Table 2).

To assess the temperature dependence of the photoionization cross section, the relative shapes of the PIE curves obtained at the experimental reservoir temperatures are compared. Figure 5a shows the comparison of the $\left[\operatorname{pyrr}_{14}\right]^{+}\left[\mathrm{NTf}_{2}\right]^{-}$mass $142 \mathrm{PIE}$ curves at $583 \mathrm{~K}$ and $613 \mathrm{~K}$. In order to try to force the curve shapes to match, rather than simply scaling the PIE curve at $583 \mathrm{~K}$ to the PIE curve at $613 \mathrm{~K}$ so that the highest points match,

Distribution A: Approved for public release; distribution unlimited 


\section{PREPRINT}

the PIE curve at $583 \mathrm{~K}$ is scaled iteratively to fit to the $613 \mathrm{~K}$ data by a least squares fit where the sum of the squares of the difference between two points at a fixed photon energy is minimized:

$$
(\mathrm{d} / \mathrm{dS}) \Sigma\left(\mathrm{SI}_{583}-\mathrm{I}_{613}\right)^{2}=0
$$

By this method, if the scaled PIE curves are identical, then $\Sigma\left(\mathrm{SI}_{583}-\mathrm{I}_{613}\right)^{2}$ would necessarily equal zero, and $\mathrm{S}=\left(\mathrm{I}_{613} / \mathrm{I}_{583}\right)$. However, if the curves do not match exactly, then $\Sigma\left(\mathrm{SI}_{583}-\mathrm{I}_{613}\right)^{2}>0$. In Figures $5 \mathrm{a}-\mathrm{b}$, for $\left[\mathrm{pyrr}_{14}\right]^{+}\left[\mathrm{NTf}_{2}\right]^{-}$the high temperature PIE curves for both mass 142 and mass 84 appear to have shifted slightly to higher intensities between 10 and $13.6 \mathrm{eV}\left(\mathrm{SI}_{583}<\mathrm{I}_{613}\right)$, and to lower intensities above $13.6 \mathrm{eV}\left(\mathrm{SI}_{583}>\mathrm{I}_{613}\right)$ relative to the low temperature PIE curves. Due to this slight shift in the PIE shape at higher temperature, in the region where the PIE intensity increases with temperature: $\mathrm{SI}_{583}<\mathrm{I}_{613}(10-13.6 \mathrm{eV})$, the Clausius-Clapeyron approach systematically overestimates the heat of vaporization. In the region where the PIE intensity decreases with temperature above $13.6 \mathrm{eV}$ where $\mathrm{SI}_{583}>\mathrm{I}_{613}$, the Clausius-Clapeyron calculation will underestimate the heat of vaporization. Because there are more points in the PIE summed calculation where $\mathrm{SI}_{583}<\mathrm{I}_{613}(8-13.6 \mathrm{eV}, 29$ points $)$ than where $\mathrm{SI}_{583}>$ $\mathrm{I}_{613},(13.8-15 \mathrm{eV}, 7$ points), the PIE summed result from the Clausius-Clapeyron calculation will systematically overestimate the actual heat of vaporization, although these effects will tend to cancel somewhat. If, instead of determining the heat of vaporization of $\left[\mathrm{pyrr}_{14}\right]^{+}\left[\mathrm{NTf}_{2}\right]^{-}$using the ratio of summed PIE intensities $\left(\mathrm{I}_{613} / \mathrm{I}_{583}=6.17\right.$, $\Delta \mathrm{H}_{\mathrm{vap}}=180.3 \mathrm{~kJ} / \mathrm{mol}$, Table 1) of mass 142 in the Clausius-Clapeyron equation, one uses the curve fitting scaling factor $\mathrm{S}=5.29$ from Figure 5a, the result is $\Delta \mathrm{H}_{\mathrm{vap}}=165.0$ $\mathrm{kJ} / \mathrm{mol}$, a reduction in the calculated value of $\Delta \mathrm{H}_{\mathrm{vap}}$ by $8.9 \% \quad$ A similar treatment for 


\section{PREPRINT}

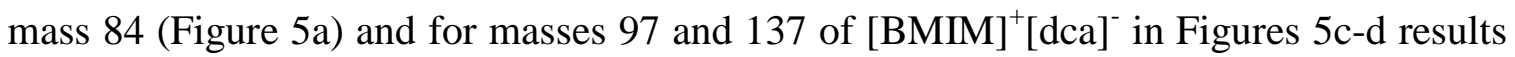
in overestimates of $1.1 \%, 6.3 \%$, and $1.1 \%$, respectively. The similar shifts in the PIE curves in Figure 5 indicate this is a systematic phenomenon. Based on $\Delta \mathrm{H}_{\mathrm{vap}}$ calculated from the measured PIE curve sum values and comparison with the scaling factor analysis which takes into account the slight temperature shift in PIE curves, the $\Delta \mathrm{H}_{\text {vap }}$ values determined by PIE summed data likely contain a systematic overestimation of 1 to $10 \%$, depending on how much the PIE curve shifts at the higher temperature. An improvement in the accuracy of this method will be to select a photon energy where the scaled PIE curves cross at $S=I_{2} / I_{1}$ and competition between photoionization cross section and ion fragmentation cancel each other out. For example, monitoring the vapor density as a function of temperature at $\sim 13.6 \mathrm{eV}$ and determining $\Delta \mathrm{H}_{\text {vap }}$ from the slope of a plot of $\ln \mathrm{I}$ versus $1 / \mathrm{T}^{18}$ would increase both the accuracy and precision of this method.

The PIE curve shift at higher temperature could be due to several factors. Competition between increased photoionization cross section and increased ion fragmentation at high temperatures may account for this observed shift. Below $13.6 \mathrm{eV}$, a larger photoionization cross section at high temperatures could explain the shift to higher intensities, and above $13.6 \mathrm{eV}$, increased ion fragmentation reduces the PIE intensity. A direct comparison of the branching ratios of masses 84/142 at two different temperatures is shown in Figure 6. Above $\sim 12 \mathrm{eV}$, the increase in branching ratio at higher temperature indicates increased ion fragmentation with increasing temperature.

There are several advantages for using photoionization versus electron impact ionization for measuring heats of vaporization for RTILs. The narrow energy spread of the light source $(0.025 \mathrm{eV})$ and soft ionization conditions minimize the effect of

Distribution A: Approved for public release; distribution unlimited 


\section{PREPRINT}

fragmentation of the parent cation and allows for appearance energies to be determined accurately. Typical electron impact ionization energies are around $70 \mathrm{eV}$, where the electron impact ionization cross section curve is large and the shape of the curve is flat for many atomic and molecular species, but molecular fragmentation to smaller species can be extensive. In this work, photoionization measurements yield a branching ratio of masses $84 / 142$ of nearly one for $\left[\operatorname{pyrr}_{14}\right]^{+}\left[\mathrm{NTf}_{2}\right]^{-}$, indicating the small extent of fragmentation of the $[\mathrm{pyrr}]^{+}$under the present soft ionization conditions versus electron impact ionization of [pyrr $\left._{14}\right]^{+}[\mathrm{dca}]^{-}$with a branching ratio of masses $84 / 142$ that is about an order of magnitude higher. ${ }^{18}$ Although fragmentation of the parent ion can be minimized by lowering the electron impact energy, the electron impact ionization cross section changes rapidly as a function of electron energy near the ionization threshold, ${ }^{30,31}$ and may be highly susceptible to thermal effects near the ionization threshold. Also, the energy spread of a typical electron gun is limited to $>0.5 \mathrm{eV}$, limiting the energy resolution in threshold measurements. Therefore, determining appearance energies of ions by electron impact ionization is difficult and has large associated uncertainties.

From the accurate determination of photoion appearance energies by the present method, comparison with theoretical energy calculations can be made. Ab initio calculations of the energetics involved in the dissociative photoionization processes (described below) are in excellent agreement with the experimentally determined photoion appearance energies. The measured mass 142 appearance energy in Figure 4 $(9.4 \pm 0.2 \mathrm{eV})$ agrees well with the $a b$ initio value of $9.2 \pm 0.1 \mathrm{eV}$ calculated at the MP2 6$31+\mathrm{G}(\mathrm{d}, \mathrm{p})$ level of theory $(0 \mathrm{~K}, \mathrm{ZPVE}$ corrected $)$ for the $\left[\operatorname{pyrr}_{14}\right]^{+}\left[\mathrm{NTf}_{2}\right]^{-}$ion pair (equation 6). An appearance energy of $10.1 \pm 0.1 \mathrm{eV}($ experimental value $=10.0 \pm 0.2 \mathrm{eV})$

Distribution A: Approved for public release; distribution unlimited 
was calculated for mass 84 , assuming elimination of $\mathrm{C}_{4} \mathrm{H}_{10}$ from the $\operatorname{pyrr}_{14}{ }^{+}$cation to form the resonance stabilized cationic structure postulated in a previous publication (equation 7), ${ }^{18}$ The electron affinity for the $\mathrm{NTf}_{2}$. radical is calculated to be $5.7 \mathrm{eV}$ at the MP2 6-31+G(d,p) level of theory.
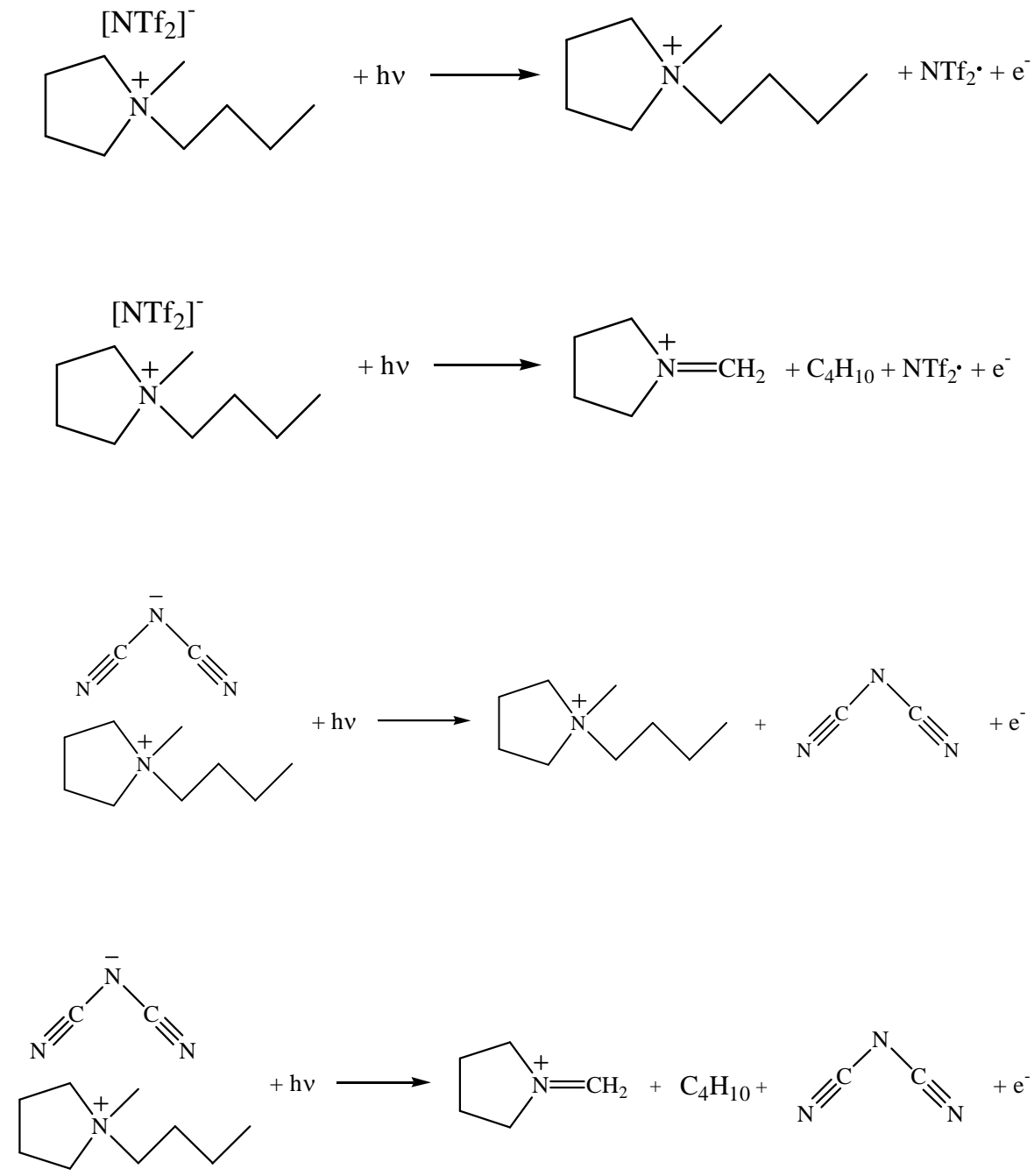

Calculation of the adiabatic ionization potentials of dicyanamide and $\left[\operatorname{pyrr}_{14}\right]^{+}[\mathrm{dca}]^{-}$at the MP2 level was precluded due to the inadequacy of a single configuration reference wavefunction for the neutral dicyanamine species. ${ }^{\text {a }}$ However, the electron affinity for the

\footnotetext{
${ }^{a}$ The need for a multiconfigurational reference in dicyanamine is evident from (a) the high degree of spin contamination present in the unrestricted Hartree-Fock (UHF) wavefunction $\left(\left\langle\mathrm{S}^{2}\right\rangle=1.303\right.$, compared to 0.5 for a pure spin doublet) and (b) the presence of multiple unphysical natural orbital occupation numbers
}

Distribution A: Approved for public release; distribution unlimited 


\section{PREPRINT}

dicyanamide radical has been determined experimentally to be $4.135 \mathrm{eV}^{32}$ Using this value along with the theoretical values in Table 3, the appearance energy for mass 84 in equation 9 is estimated to be $8.73 \pm 0.1 \mathrm{eV}$, and is in excellent agreement with the experimental appearance energy for mass 84 in the $\left[\operatorname{pyrr}_{14}\right]^{+}[\mathrm{dca}]^{-}$dissociative photoionization of $8.8 \pm 0.2 \mathrm{eV}$. The estimated appearance energy of the intact $\left[\operatorname{pyrr}_{14}\right]^{+}$ cation in equation 8 is $7.81 \mathrm{eV}$. However, the experimental signal to noise ratio for this species was not sufficient to determine its appearance energy although it was detectable at higher energies. From M06 calculations, the vertical and adiabatic ionization potentials of $\left[\operatorname{pyrr}_{14}\right]^{+}[\mathrm{dca}]^{-}$are $7.8 \mathrm{eV}$ and $7.7 \mathrm{eV}$ respectively, and the M06 vertical ionization potential agrees well with the MP2 vertical ionization potential of $7.7 \mathrm{eV}$. Overall, the agreement between theory and experiment supports the dissociative photoionization of isolated cation-anion ion pairs in the gas phase.

\section{Conclusions}

Heats of vaporization for several room temperature ionic liquids have been determined by effusive beam VUV photoionization mass spectrometry. The photoionization cross section is considered to be temperature independent when using the PIE curves for the Clausius-Clapeyron analysis. We estimate a positive systematic error of up to $10 \%$ for this assumption. After thermal correction to $298.15 \mathrm{~K}$, the $\Delta \mathrm{H}_{\text {vap values }}$ of $[\mathrm{BMIM}]^{+}[\mathrm{dca}]^{-}$and $\left[\mathrm{pyrr}_{14}\right]^{+}[\mathrm{dca}]^{-}$reported here are in reasonable agreement with the previously reported experimental values. For $\left[\operatorname{pyrr}_{14}\right]^{+}\left[\mathrm{NTf}_{2}\right]^{-}, \Delta \mathrm{H}_{\mathrm{vap}}(298.15 \mathrm{~K})$ is calculated to be $195 \pm 19 \mathrm{~kJ} \mathrm{~mol}^{-1}$, which has not been reported previously. Detection of the intact $\left[\text { pyrr }_{14}\right]^{+}$cation is indicative of the presence of neutral cation-anion ion pairs in

(see Gordon, M. S.; Schmidt, M. W.; Chaban, G. M.; Glasemann, K. R. Journal of Chemical Physics 1999, $110,4199)$ obtained from the second order Z-averaged perturbation theory (ZAPT(2)) relaxed density matrix.

Distribution A: Approved for public release; distribution unlimited 
the effusive beam which dissociate to form $\left[\operatorname{pyrr}_{14}\right]^{+}$and neutral $\mathrm{NTf}_{2}$. at low VUV photon energy. A second dissociation pathway detected is the efficient fragmentation of $\left[\text { pyrr }_{14}\right]^{+}$to produce mass 84 . Together, these experimental heats of vaporization, photoionization appearance energies, and ab initio calculations support a vaporization mechanism for RTILs as intact cation-anion ion pairs.

\section{Acknowledgements}

Funding for this work was provided by the Air Force Office of Scientific Research under Contract No. FA9300-06-C-0023 with the Air Force Research Laboratory, Edwards AFB, CA 93524, and grant FA9550-07-1-0059 to the University of California, Berkeley. Research at the Advanced Light Source is supported by the Director, Office of Science, Office of Basic Energy Sciences of the U.S. Department of Energy under Contract No. DE-AC02-05CH11231 at the Lawrence Berkeley National Laboratory. SRL gratefully acknowledges the generous support of a Morris Belkin Visiting Professorship at the Weizmann Institute of Science. This research is partly supported by the Air Force Summer Faculty Fellowship Program administered by the ASEE (contract number FA9550-07-C-0052). Special thanks to Dr. Jerry Boatz for helpful discussions on MP2 calculations and donation of CPU time.

Distribution A: Approved for public release; distribution unlimited 


\section{PREPRINT}

\section{Figure Captions}

Figure 1. N-butyl-N-methylpyrrolidinium bistrifluorosulfonylimide $\left[\operatorname{pyrr}_{14}\right]^{+}\left[\mathrm{NTf}_{2}\right]^{-}$, a room temperature ionic liquid.

Figure 2. Ionic liquid effusive beam source.

Figure 3. Mass spectrum of $\left[\mathrm{pyrr}_{14}\right]^{+}\left[\mathrm{NTf}_{2}\right]^{-}$at $15.0 \mathrm{eV}$ photon energy and source temperature of $613 \mathrm{~K}$.

Figure 4. Photoionization efficiency (PIE) curves of $\left[\operatorname{pyrr}_{14}\right]^{+}\left[\mathrm{NTf}_{2}\right]^{-}$for mass 142 at 583 and $613 \mathrm{~K}$ and mass 84 at $613 \mathrm{~K}$.

Figure 5. Least-squares fit analyses of the PIE curves for (a) $\left[\operatorname{pyrr}_{14}\right]^{+}\left[\mathrm{NTf}_{2}\right]^{-}$of mass 142 at $583 \mathrm{~K}$ relative to $613 \mathrm{~K}$, (b) $\left[\operatorname{pyrr}_{14}\right]^{+}\left[\mathrm{NTf}_{2}\right]^{-}$of mass 84 at $583 \mathrm{~K}$ relative to $613 \mathrm{~K}$, (c) $[\mathrm{BMIM}]^{+}[\mathrm{dca}]^{-}$of mass 97 at $468 \mathrm{~K}$ relative to $483 \mathrm{~K}$, and (d) $[\mathrm{BMIM}]^{+}[\mathrm{dca}]^{-}$of mass 137 at $468 \mathrm{~K}$ relative to $483 \mathrm{~K}$.

Figure 6. Mass $84 / 142$ branching ratios for $\left[\operatorname{pyrr}_{14}\right]^{+}\left[\mathrm{NTf}_{2}\right]^{-}$at $583 \mathrm{~K}$ and $613 \mathrm{~K}$ as a function of photon energy.

Distribution A: Approved for public release; distribution unlimited 


\section{PREPRINT}
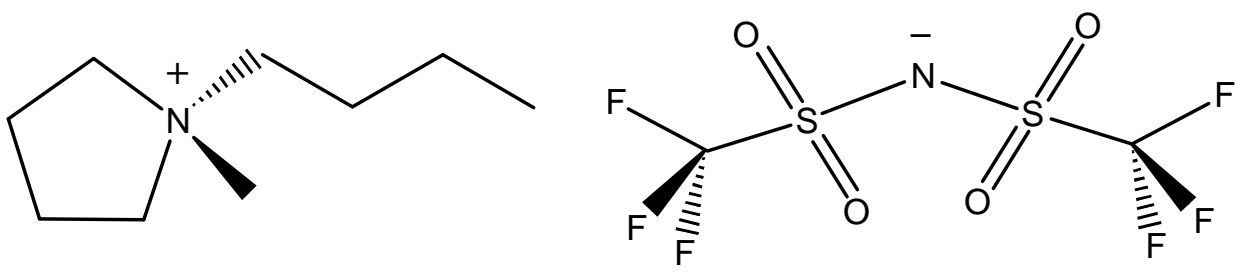

Figure 1.

Distribution A: Approved for public release; distribution unlimited 


\section{PREPRINT}

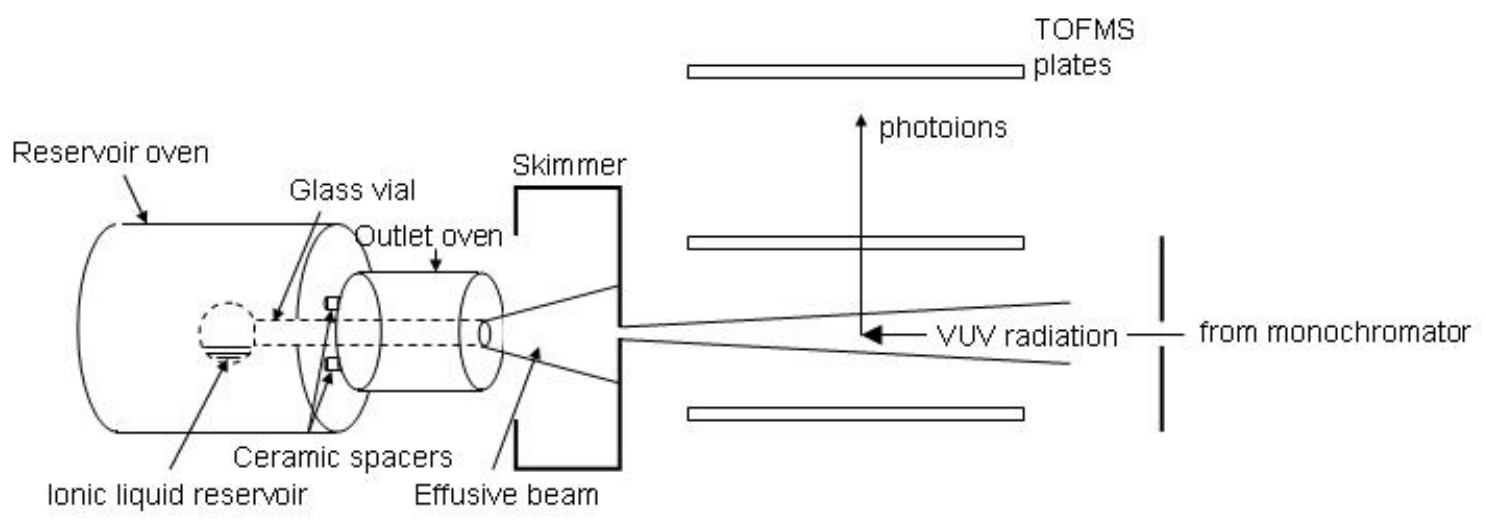

Figure 2.

Distribution A: Approved for public release; distribution unlimited 


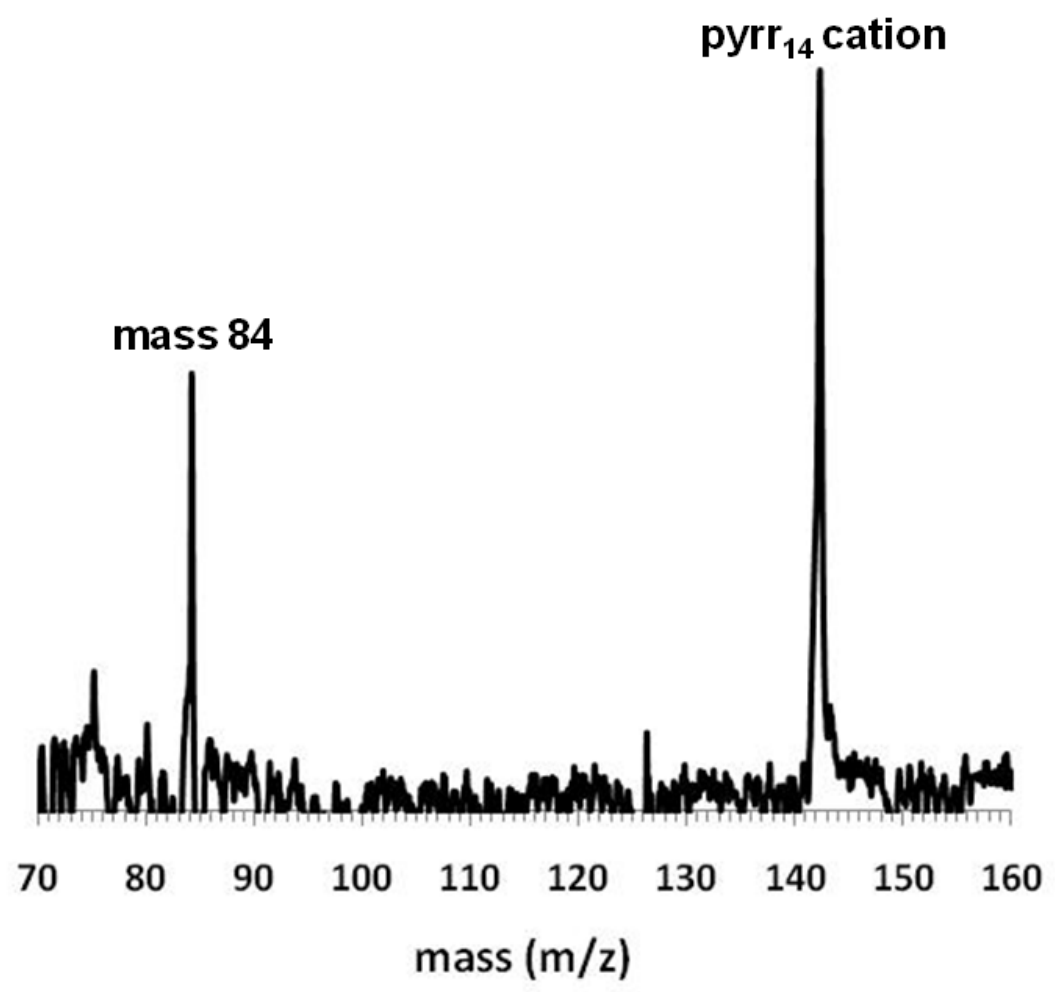

Figure 3.

Distribution A: Approved for public release; distribution unlimited 


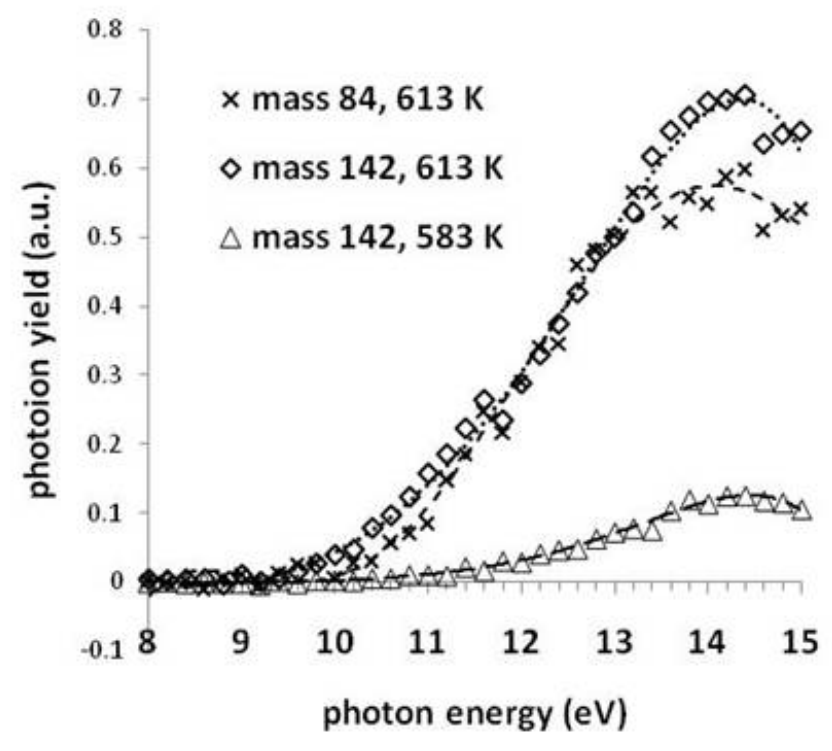

Figure 4.

Distribution A: Approved for public release; distribution unlimited 

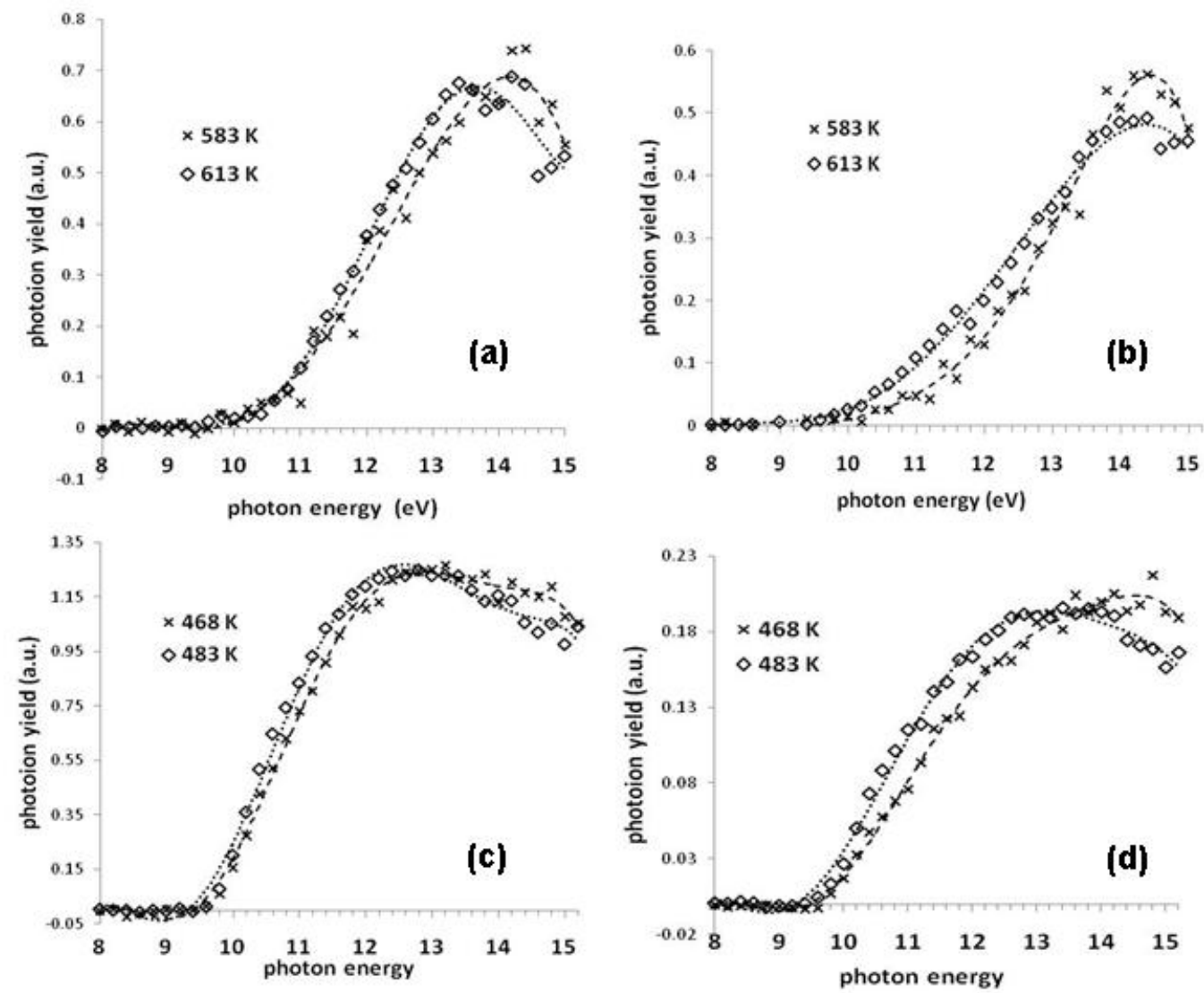

Figure 5.

Distribution A: Approved for public release; distribution unlimited 


\section{PREPRINT}

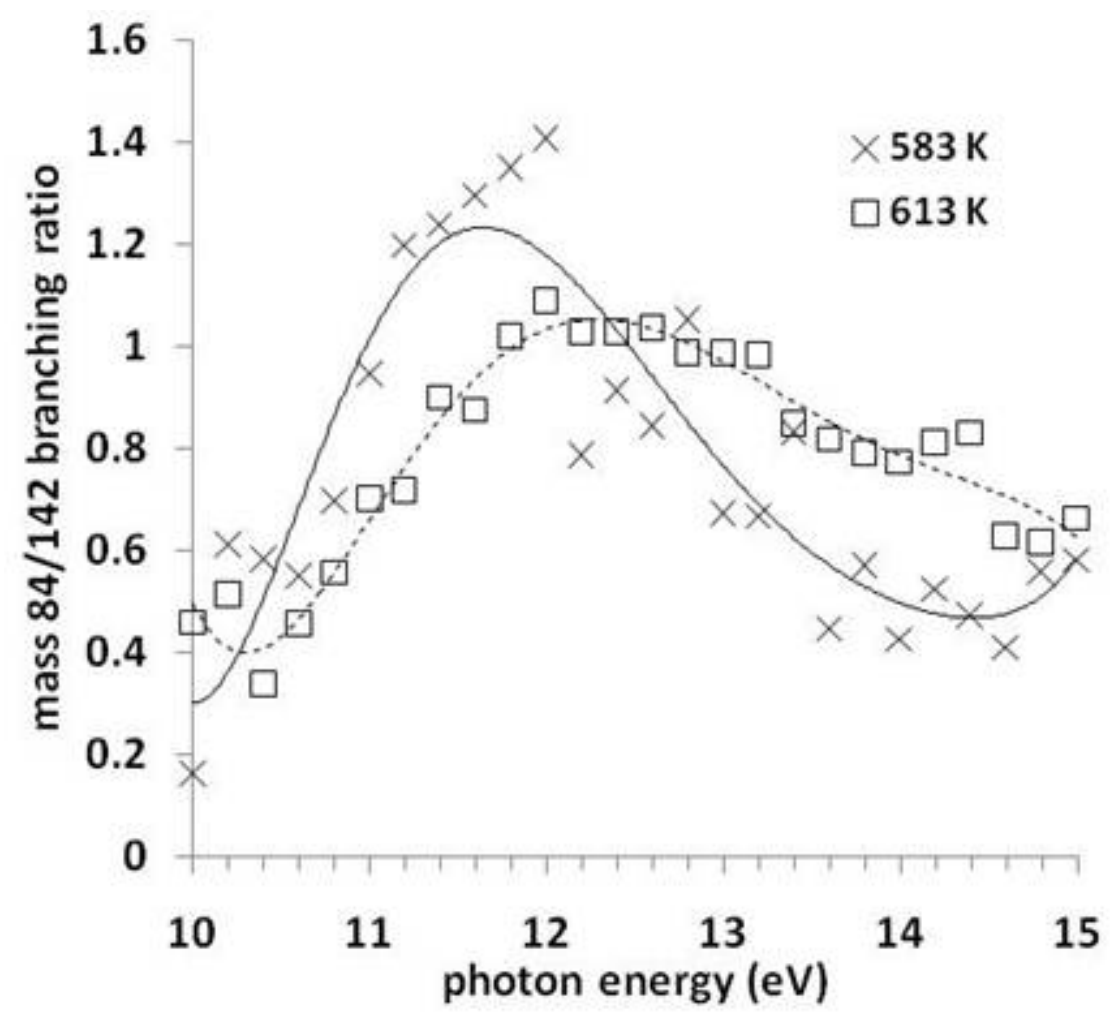

Figure 6. 


\section{PREPRINT}

(1) Chambreau, S. D.; Schneider, S.; Rosander, M.; Hawkins, T.; Gallegos, C. J.; Pastewait, M. F.; Vaghjiani, G. L. J. Phys. Chem. A 2008, 112, 7816.

(2) Gao, H.; Joo, Y.-H.; Twamley, B.; Zhou, Z.; Shreeve, J. n. M. Angew. Chem. Int. Ed. 2009, 48, 2792.

(3) Hawkins, T.; Rosander, M.; Vaghjiani, G. L.; Chambreau, S. D.; Drake, G.; Schneider, S. Energy Fuels 2008, 22, 2871.

(4) Schneider, S.; Hawkins, T.; Rosander, M.; Mills, J. D.; Vaghjiani, G. L.; Chambreau, S. D. Z. Inorg. Chem. 2008, 47, 6082.

(5) Earle, M. J.; Esperança, J. M. S. S.; Gilea, M. A.; Canongia Lopes, J. N.; Rebelo, L. P. N.; Magee, J. W.; Seddon, K. R.; Widegren, J. A. Nature 2006, 439, 831.

(6) Leal, J. P.; Minas da Piedade, M. E.; Canongia Lopes, J. N.;

Tomaszowska, A. A.; Esperança, J. M. S. S.; Rebelo, L. P. N.; Seddon, K. R. J. Phys.

Chem. B 2009, 113, 3491.

(7) Leal, J. P.; Esperança, J. M. S. S.; Minas da Piedade, M. E.; Canongia Lopes, J. N.; Rebelo, L. P. N.; Seddon, K. R. J. Phys. Chem. A 2007, 111, 6176.

(8) Rebelo, L. P. N.; Canongia Lopes, J. N.; Esperança, J. M. S. S.; Filipe, E. J. Phys. Chem. B 2005, 109, 6040.

(9) Zaitsau, D. H.; Verevkin, S. P.; Paulechka, Y. U.; Kabo, G. J.; Sevruk, V. M. J. Chem. Eng. Data 2003, 48, 1393.

(10) Emel'yanenko, V. N.; Verevkin, S. P.; Heintz, A. J. Am. Chem. Soc. 2007, $129,3930$.

(11) Paulechka, Y. U.; Kabo, G. J.; Blokhin, A. V.; Vydrov, O. A.; Magee, J. W.; Frenkel, M. J. Chem. Eng. Data 2003, 48, 457.

(12) Paulechka, Y. U.; Zaitsau, D. H.; Kabo, G. J.; Strechan, A. A. Thermochim. Acta 2005, 439, 158.

(13) Zaitsau, D. H.; Kabo, G. J.; Strechan, A. A.; Paulechka, Y. U.; Tscherisch, A.; Verevkin, S. P.; Heintz, A. J. Phys. Chem. A 2006, 110, 7303.

(14) Dzyuba, S. V.; Bartsch, R. A. ChemPhysChem 2002, 3, 161.

(15) Ngo, H. L.; LeCompte, K.; Hargens, L.; McEwen, A. B. Thermochim. Acta 2000, 357-358, 97.

(16) Wooster, T. J.; Johanson, K. M.; Fraser, K. J.; MacFarlane, D. R.; Scott, J. L. Green Chem. 2006, 8, 691.

(17) Strasser, D.; Goulay, F.; Kelkar, M. S.; Maginn, E. J.; Leone, S. R. J. Phys. Chem. A 2007, 111, 3191.

(18) Emel'yanenko, V. N.; Verevkin, S. P.; Heintz, A.; Corfield, J.-A.; deyko, A.; Lovelock, K. R. J.; Licence, P.; Jones, R. G. J. Phys. Chem. B 2008, 112, 11734.

(19) Armstrong, J. P.; Hurst, C.; Jones, R. G.; Licence, P.; Lovelock, K. R. J.; Satterly, C. J.; Villar-Garcia, I. J. PCCP 2007, 9, 982.

(20) Gross, J. H. J. Am. Soc. Mass Spectrom. 2008, 19, 1347.

(21) de Andrade, J.; Böes, E. S.; Stassen, H. J. Phys. Chem. B 2002, 106, 13344.

(22) Köddermann, T.; Paschek, D.; Ludwig, R. ChemPhysChem 2008, 9, 549.

(23) Kroon, M. C.; Buijs, W.; Peters, C. J.; Witkamp, G.-J. Thermochim. Acta 2007, 465, 40 .

(24) Kelkar, M. S.; Maginn, E. J. J. Phys. Chem. B 2007, 111, 9424.

(25) Frisch, M. J. e. a. "Gaussian 03," Gaussian, Inc., 2003.

Distribution A: Approved for public release; distribution unlimited 
(26) Zhao, Y.; Truhlar, D. G. Theor. Chem. Account. 2008, 120, 215.

(27) Gordon, M. S.; Schmidt, M. W. Advances in electronic structure theory: GAMESS a decade later. In Theory and Applications of Computational Chemistry: the first forty years; Dykstra, C. E., Frenking, G., Kim, K. S., Scuseria, G. E., Eds.; Elsevier: Amsterdam, 2005; pp 1167.

(28) Schmidt, M. W.; Baldridge, K. K.; Boatz, J. A.; Elbert, S. T.; Gordon, M. S.; Jensen, J. H.; Koseki, S.; Matsunaga, N.; Nguyen, K. A.; Su, S.; Windus, T. L.;

Dupuis, M.; Montgomery, J. A. J. Comput. Chem. 1993, 14, 1347.

(29) Swiderski, K.; McLean, A.; Gordon, C. M.; Vaughn, D. H. Chem.

Commun. 2004, 2178.

(30) Kim, Y.-K.; Hwang, W.; Weinberger, N. M.; Ali, M. A.; Rudd, M. E. Journal of Chemical Physics 1996, 106, 1026.

(31) Probst, M.; Deutsch, H.; Becker, K.; Märk, T. D. Int. J. Mass. Spectrom. 2001, 206, 13.

(32) Jagoda-Cwiklik, B.; Wang, X.-B.; Woo, H.-K.; Yang, J.; Wang, G.-J.;

Zhou, M.; Jungwirth, P.; Wang, L.-S. J. Phys. Chem. A 2007, 111, 7719.

Distribution A: Approved for public release; distribution unlimited 